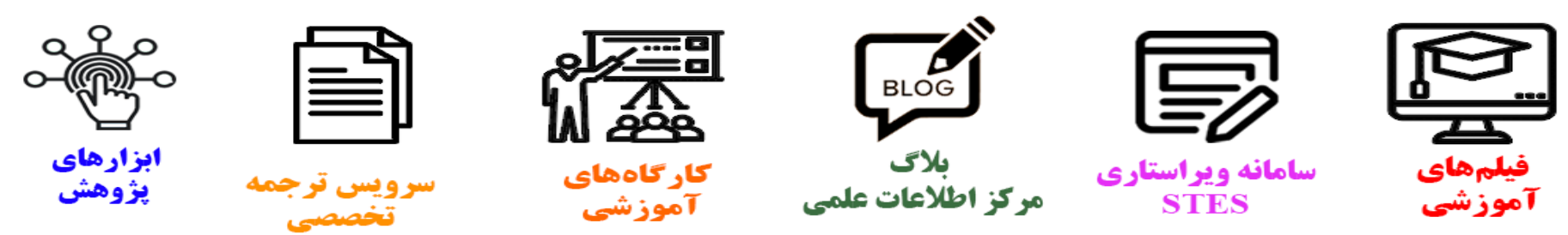

\title{
(c)
}

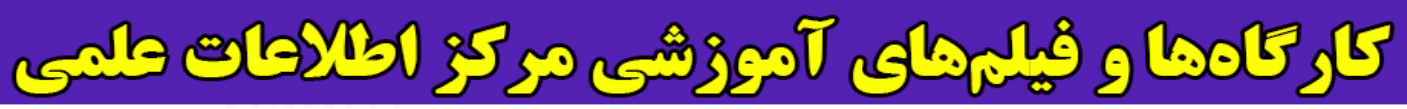
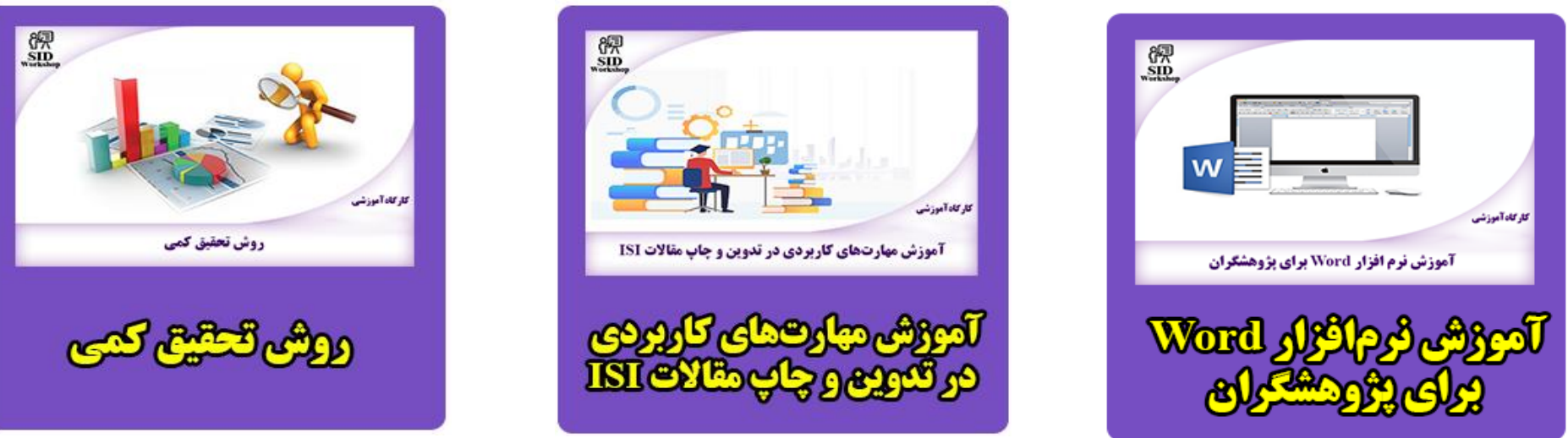


\title{
International Journal of Engineering
}

Journal Hom e page: ww w. ije.ir

\section{Plasticity Effect on Residual Stresses Measurement using Contour Method}

\author{
A.H. Mahmoudi* , A. R. Hosseinzadeh, M. Jooya \\ Department of Mechanical Engineering, University of Bu-Ali Sina, Hamedan, Iran
}

\section{$P A P E R \quad I N F O$}

Paper history:

Received 01 May 2013

Received in revised form 11 May 2013

Accepted 16 May 2013

\section{Keywords:}

Contour Method

Residual Stress

Plasticity

Finite Element

\section{A $B \begin{array}{lllllll} & S & T & A & C & T\end{array}$}

Residual stresses have become an important player in the field of structural integrity for many years. Exact knowledge of residual stress distributions is essential in designing the engineering components as unexpected failures are inevitable wherever such stresses are ignored. There are many residual stresses measurement techniques including destructive and non-destructive ones. Among the mechanical strain relief (MSR) techniques, contour method is one of the youngest. Contour method relies on the material removal similar to other MSR techniques. In this method a part is carefully cut into two pieces along a flat plane, causing the residual stress normal to the cutting plane to relax. However, similar to other MSR techniques, plasticity can have a great influence on the accuracy of the results. In the present work, effect of plasticity on the residual stress measurement using contour method is investigated. Quenching is employed to induce residual stresses within the samples. To create different levels of plasticity, the samples were quenched at three different temperatures, $500^{\circ} \mathrm{C}$, $700^{\circ} \mathrm{C}$ and $850^{\circ} \mathrm{C}$. The residual stresses were then measured using contour method. Furthermore, the contour method procedure is simulated using finite element analysis to compare with the experimental results.

\section{INTRODUCTION}

Residual stresses are those stresses that remain in a body when it is under no mechanical loading and at rest and equilibrium with its surroundings [1]. The engineering structures properties such as fatigue life, corrosion, distortion, stability of dimensions, resistance, and brittle fracture are affected by residual stresses significantly $[2,3]$. Residual stresses have a significant role in many material failure processes. Due to such role, the knowledge of residual stress is necessary for accurate prediction of any engineering structure failure. Besides, prediction of residual stresses is too difficult due to their dependence on many manufacturing processes (and previous service life); thus, residual stresses determination is a forcible step in the design of engineering parts and in the estimation of their life under service loadings [4]. Therefore, if residual stresses are not known, they can cause unexpected failure when combined with applied stresses [5]. Mostly, tensile residual stresses cause problems in this

\footnotetext{
* Corresponding Author Email: a.h.mahmoudi@gmail.com (A .H. Mahmoudi)
}

field that can create many undesirable phenomena on fatigue life and cause stress corrosion and crack propagation in materials. However, compressive stresses can have an advantageous effect in these cases, by preventing crack growth.

Many experimental methods exist for determining the residual stresses in engineering structures. These methods can be categorized into destructive, semidestructive and non-destructive techniques. The MSR techniques rely on the measurement of deformations where the relaxation of residual stresses in specimen occurs following the material removal. The common destructive and semi-destructive methods that used to measure residual stresses in structural components are: hole-drilling, ring-coring, deep-hole, crack compliance, contour method and sectioning $[5,6]$.

Contour method is a relatively new and powerful destructive method for residual stress measurements and has high resolution and can be used to high range of materials and for large components [7] and unlike neutron diffraction, it is relatively insensitive to small changes in material chemistry [8] that was first proposed in 2001 where the contour method was performed on a bent steel beam having a well-known 
residual stress distribution [9]. Later, the ability of the contour method was explained on a TIG BS4360 steel weld to measure a complex $2 \mathrm{D}$ stress distribution along the weld direction [10]. Contour method involves two main steps; first the experimental part which follows by a numerical simulation. In contour method, a part is cut in half. Then, the relaxed contours of new surfaces are measured. Average calculation of two surfaces displacements is applied to the cut surface of the body as boundary conditions in a finite element model [9]. With correct application of these steps it is possible to determine the residual stress through the plane of the cut. Due to the experimental limitations, only deformations normal to the cut surface can be measured which can only result in the normal component of the residual stresses. However, in theory the contour method can measure all components of such stress [11]. Contour method for measuring residual stresses is based on the Bueckner's superposition principle [12]. Similar to the other relaxation methods, there are several assumptions during cutting process that are: cutting along a favorite plane is straight and doesn't change the relaxed displacements and residual stress relaxation is completely elastic. Contour method has been employed on different samples with various residual stress origins such as welding, quenching, hammer peening, cold working and etc. For example, residual stresses generated by welding have been measured and then compared with the results of neutron diffraction $[10,13$, 14] or with finite element simulations [15]. The residual stresses induced by hammer peeing [16] and impact in a high-strength low alloy steel [17] were also measured using contour method. The residual stresses obtained by quenching and cold-working have also been measured [18]. Contour method has also been employed to measure residual stresses of a sample bead-on-plate of a 316L stainless steel [19] and in the compressor blades [20].

Several research works have been performed to improve the performance of the contour method, i.e. recommendation of multiple cut that can give multiple stress components [21, 22], minimizing the error in measurements [23] and determination of the plasticity effect [24]. For high levels of residual stresses, during the cutting process, stress concentration may cause plasticity which does not allow the stresses to relax completely. Yet, when the released residual stresses are close to the yield stress, cutting process causes formation of a plastic region on the cutting surfaces [1, $25]$.
In the present work, the effect of plasticity was studied in contour method using different levels of residual stresses. There are different methods of residual stress generation such as welding, shot peening and etc. Quenching is a method of hardening in industrial processes, but it can be used to generate residual stresses in a sample [25]. Finite element analyses were then carried out to simulate the process. Furthermore, the measured stresses were compared with those predicted. Then, the finite element analyses were carried out to study the effect of plasticity. It was found that the cutting direction have considerable influence on how residual stresses were redistributed.

\section{EXPERIMENTS}

2. 1. Sample Preparation and Quenching Process The quenching was employed to induce residual stresses within the appropriate components due to its repeatability features as well as having control on the required residual stress levels within the samples. Several primary tasks were done to prepare the specimens. These tasks included choosing the material, size and shape of the specimens and performing the quenching process to generate residual stresses. Authors have already measured the heat transfer coefficient during the cooling process [26] which was used in the finite element analyses.

The samples were made of $316 \mathrm{~L}$ stainless steel. The chemical compositions of samples are shown in Table1. Typical applications of this grade of steel are: pharmaceuticals, marine usage, preparation of food devices especially in chloride environments, architectural applications, medical implants, including pins, screws and orthopedic implants like total hip and knee replacements and fasteners. Three cylindrical samples were prepared with $60 \mathrm{~mm}$ diameter and 60 $\mathrm{mm}$ height. The samples were quenched at three different temperatures. They first heated up to $500^{\circ} \mathrm{C}$, $700^{\circ} \mathrm{C}$ and $850^{\circ} \mathrm{C}$ (Figure 1). These levels of temperature were chosen in a way that no phase transformation occurred during the quenching process. The samples were then cooled down using a water spray cooling rig (Figure 2). It is important to notice that the results of present study can be generalized to other cases with different residual stress sources other than quenching as the measurement technique cannot distinguish between different sources of stress. Next, the contour method was employed for measuring the residual stress field induced by the quenching process.

TABLE 1. Percental chemical composition of $316 \mathrm{~L}$ stainless steel

\begin{tabular}{ccccccccccccccc}
\hline $\mathbf{C}$ & $\mathbf{S i}$ & $\mathbf{M n}$ & $\mathbf{P}$ & $\mathbf{S}$ & $\mathbf{C r}$ & $\mathbf{M o}$ & $\mathbf{N i}$ & $\mathbf{A l}$ & $\mathbf{C o}$ & $\mathbf{C u}$ & $\mathbf{N b}$ & $\mathbf{T i}$ & $\mathbf{V}$ & $\mathbf{W}$ \\
\hline 0.026 & 0.446 & 1.48 & 0.0448 & 0.0118 & 16.6 & 2.13 & 10.02 & 0.0025 & 0.182 & 0.471 & 0.0146 & 0.002 & 0.0625 & 0.0483 \\
\hline
\end{tabular}




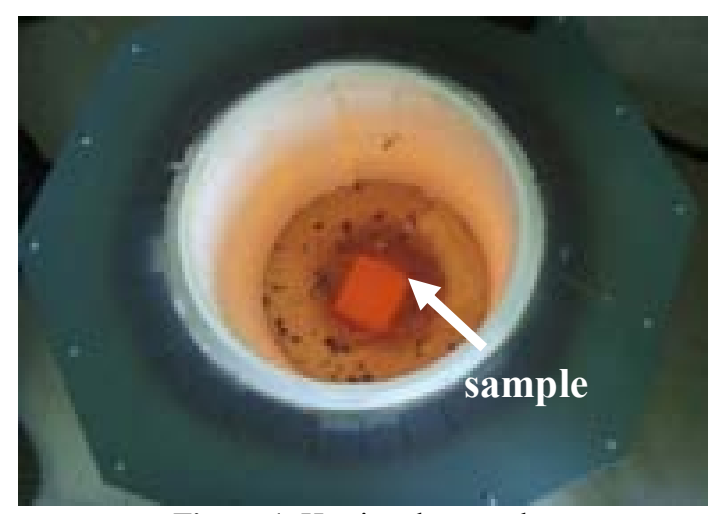

Figure 1. Heating the samples

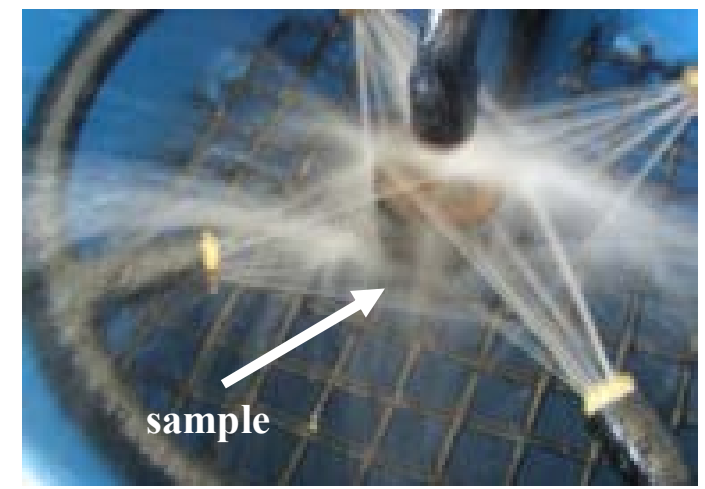

Figure 2. Cooling rig and the sample

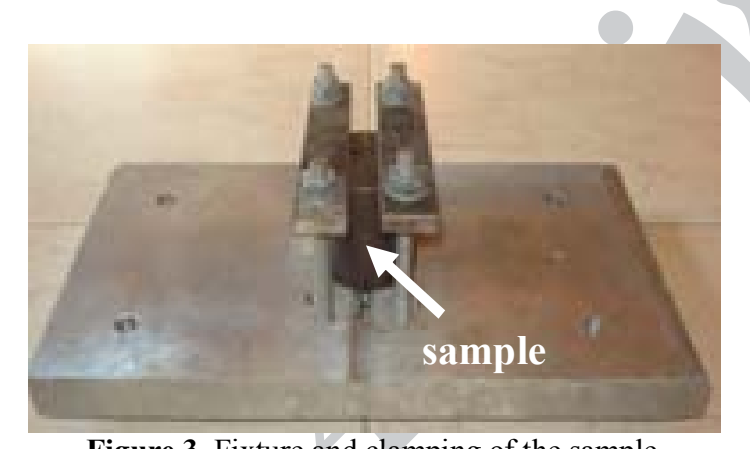

Figure 3. Fixture and clamping of the sample

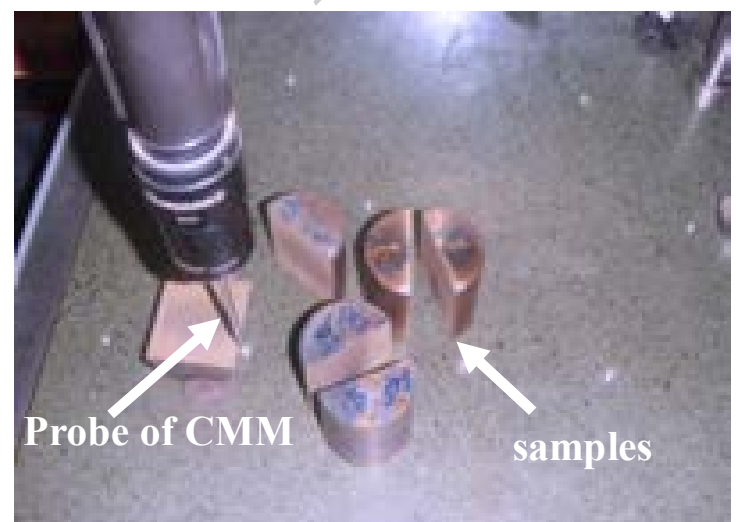

Figure 4. Measuring the deviation of cut surfaces by CMM
2. 2. Cutting Process The first and most important step of contour method process is cutting the specimens. Contour measurement, data setting and stress obtaining as the following procedures of cutting is dependent on the quality of the cutting. The ideal machining process for cutting the parts in half must be accurately straight and must not cause any plastic deformation. It is also important that the cutting device does not remove any further material from already cut faces. Therefore, the Wire Electric Discharge Machining (Wire EDM) was the best available choice. The specimen was restrained carefully to avoid any movement during the cutting process. For this purpose, a fixture was designed and made to restrain the cylinders (Figure 3 ). The diameter of the brass wire used in the cutting process was 0.25 $\mathrm{mm}$, removing around $0.35 \mathrm{~mm}$ width of the material. Cutting speed was chosen low enough to minimize stress change.

2. 3. Deformations Measurements Measuring the deformations of cut surfaces was performed following the cutting process using a Coordinate Measuring Machine (CMM) that is shown in Figure 4. The measurement was performed on both halves of each specimen. The measurements were carried out along lines from one edge of the specimen to the opposite side. During the measurements, probe kept a continuous contact with the specimen surface with an applied force. Diameter of the tip of the CMM probe was $1 \mathrm{~mm}$ with an accuracy of $0.1 \mu \mathrm{m}$. Coordinates were measured in about 2500 points on about 41 lines (distance between each line was $1.5 \mathrm{~mm}$ ) on both cut surfaces. Output of CMM was an AutoCAD file and a map of coordinates of the desired points was derived. The measured displacements in each half of the specimen were approximately the same shape but not the same amplitude. This difference might be a result of having the cut not centered between the clamps. Such asymmetries might have caused the plane of the cut to move slightly as stresses are released, and the cut proceeded on a different plane. By averaging the results of the two contours prior of stress calculations this deviation can be taken care off. The amount of error in measurement by the CMM is around 5 microns which resulted in $\pm 8 \mathrm{MPa}$ error in calculated stresses. Error bars are also included in the graghs of experimental results.

2.4. Smoothing Process The raw measured displacements must be processed before being applied as boundary conditions [13]. The CMM measurements may encounter problems in regions near the sample edges and even record false points when the force on the probe is set too low or too high. Displacements obtained from CMM in all three samples contained fair amounts of noise. 


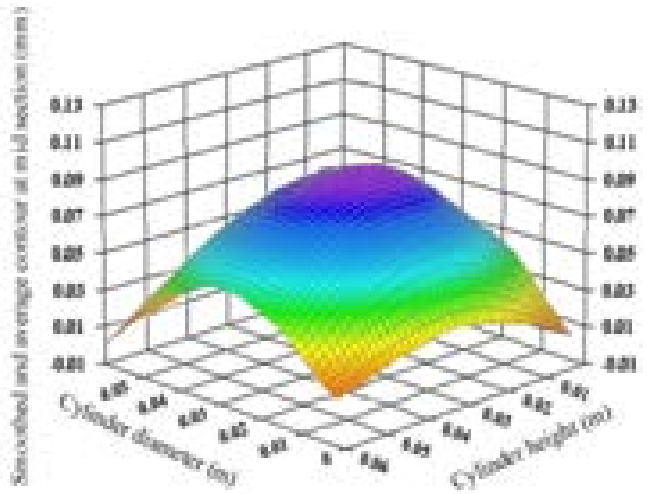

(a)

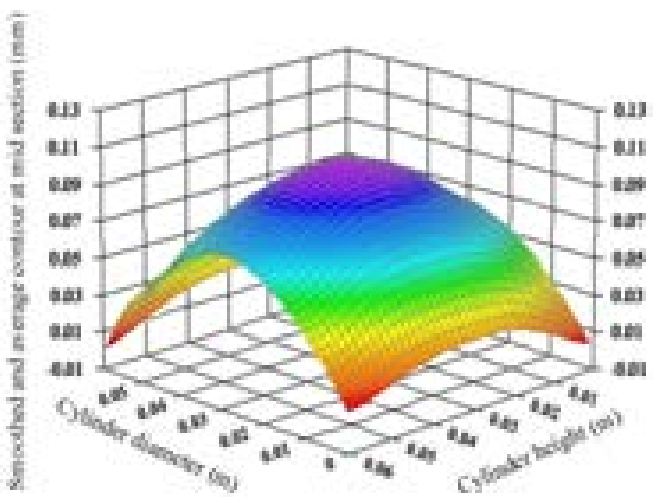

(b)

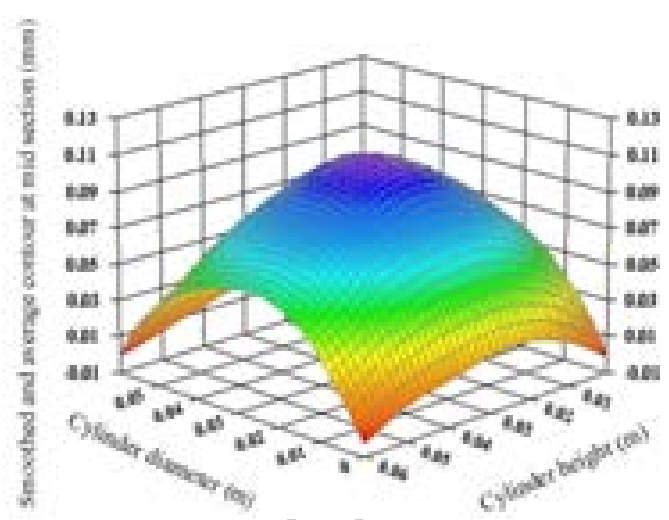

(c)

Figure 5. Averaged of smoothed contour in cut surface of cylinders quenched at (a) $500^{\circ} \mathrm{C}$, (b) $700^{\circ} \mathrm{C}$, (c) $850^{\circ} \mathrm{C}$.

The noises can be a result of the surface roughness that was picked up by the CMM. Therefore, the distribution of the displacements must be smoothened in order to remove undesirable noises. The measured data were fitted to a fourier series bivariate order $2 \times 5$ to smooth out the noise. This was also done to enable the evaluation at arbitrary locations which are grids corresponding to the finite element nodes. The values at nodal locations were then applied to the cut surface as boundary conditions. The average of the two surfaces were then calculated and reversed subsequently. The smoothed contours in both halves for three samples are shown in Figure 5. As shown in Figure 5, on the sample quenched at $500^{\circ} \mathrm{C}$, peak-to-valley distance was about $70 \mu \mathrm{m}$ while it was about $95 \mu \mathrm{m}$ for the specimen quenched at $700^{\circ} \mathrm{C}$. The peak-to-valley distance for the sample quenched at $850^{\circ} \mathrm{C}$ was about $115 \mu \mathrm{m}$. This relative distance in three samples clearly showed that the level of stresses at $850^{\circ} \mathrm{C}$ was more than other cases and it was the least for the specimen quenched at $500^{\circ} \mathrm{C}$.

2. 5. Applying Deformations to Model The averages of the measured displacements were fed to a finite element model of half cylinders as boundary conditions of the corresponding nodes. Data setting at this step was carefully performed to apply a correct sample point displacements to corresponding nodes in the finite element model. Simulation of the half cylinder was accomplished using the commercial code ABAQUS [27]. Figure $6 a$ shows the three dimensional finite element model of the half cylinder with the applied displacements on the nodes. Deformation is exaggerated in the figure by a factor of 70 to provide a better demonstration. Having the displacement applied to the model as boundary conditions, the residual stress distributions were obtained. The distributions of the residual stress components normal to the cut plane along paths $\mathrm{AB}$ and $\mathrm{CD}$ (see Figure $6 \mathrm{~b}$ ) for all three cylinders are shown in Figure $7 \mathrm{a}$ and $7 \mathrm{~b}$, respectively. Note that all results reported in this paper are along centerline (line $\mathrm{AB}$ ) and the axis of cylinder (line $\mathrm{CD}$ ) in the cut surface. Also, the cutting direction was parallel to line $\mathrm{AB}$. Along path $\mathrm{AB}$, the sample quenched at $850^{\circ} \mathrm{C}$ showed higher level of residual stresses and the cylinder quenched at $500^{\circ} \mathrm{C}$ illustrated the lowest. The measured residual stresses along path $\mathrm{CD}$ were more complicated. It can be seen in Figure $7 \mathrm{~b}$ that the sequence of residual stress distributions was not the same as line $A B$ for some part of the specimens. This can be due to some experimental error which might have happened during the measurements.

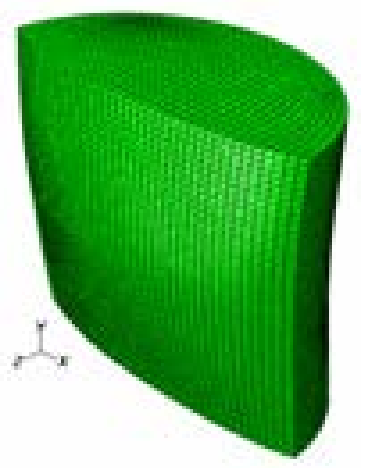

(a) 


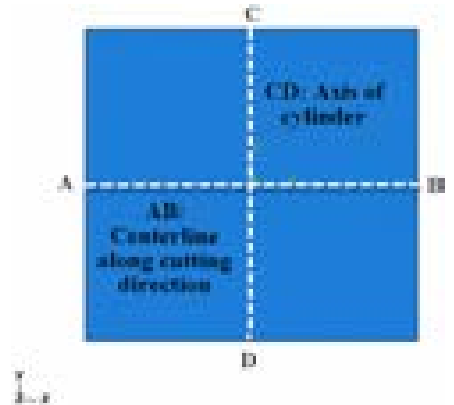

(b)

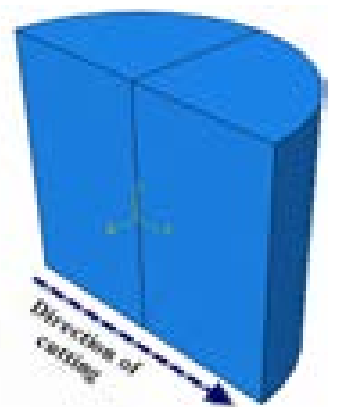

(c)

Figure 6. (a) The 3D finite element model of the half cylinder with exaggerated applied displacements by a factor of 70 , (b) A schematic of centerline (line $\mathrm{AB}$ ) and axis of model (line $\mathrm{CD})$ and (c) cutting direction.

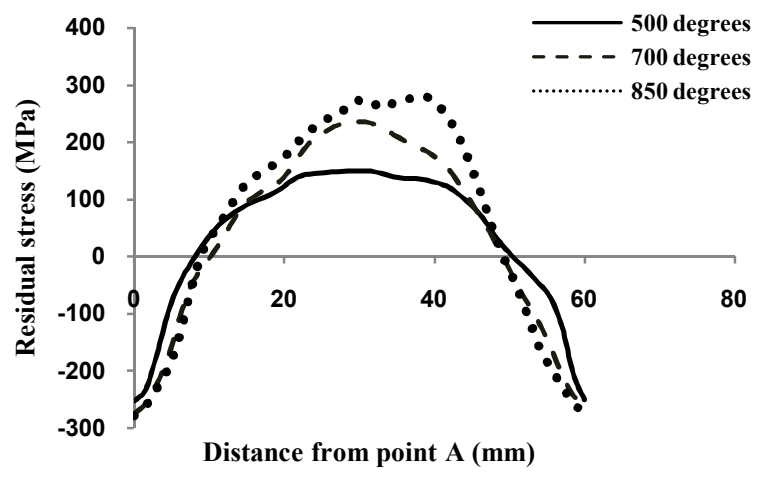

(a)

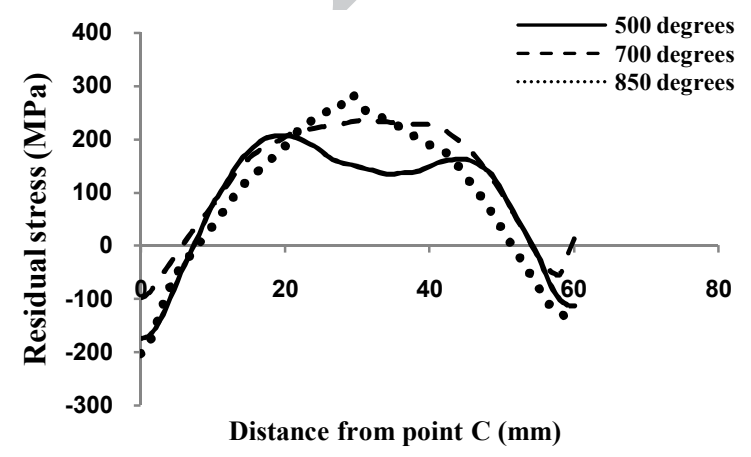

(b)

Figure 7. Residual stresses obtained by contour method in three samples, (a) along line $\mathrm{AB}$ and (b) along axis of cylinder (line CD).

\section{FINITE ELEMENT ANALYSES}

3. 1. Quenching Simulation A numerical model of whole process was carried out using finite element analysis. A model of cylinder with the same size of the experimental samples was created. Material properties of $316 \mathrm{~L}$ stainless steel are listed in Table 2. A three dimensional uncoupled thermal and stress analysis was employed. The simulation was carried out in two main steps. First, a thermal analysis was performed, and then the temperature histories obtained for all nodes were applied as initial conditions in the stress analysis. The initial temperatures of the models were set to be at three different levels of $500^{\circ} \mathrm{C}, 700^{\circ} \mathrm{C}$ and $850^{\circ} \mathrm{C}$. Cylinders were then quenched with a transient heat-transfer. Time period for this step was considered to be around $6 \mathrm{~min}$ and water temperature to be $23^{\circ} \mathrm{C}$ similar to what happened during the experiments. Finally, the residual stresses following the cooling down were extracted from the model. Results of the finite element predictions in three samples are shown in Figure 8a and 8b (along $\mathrm{AB}$ and $\mathrm{CD}$, respectively). Figure $8 \mathrm{a}$ and $8 \mathrm{~b}$ illustrate the residual stresses along the horizontal and the vertical paths, respectively. As expected, the residual stresses of the cylinder quenched at $850^{\circ} \mathrm{C}$ had the highest level and the $500^{\circ} \mathrm{C}$ one induced the lowest level. Also, the regions of compressive residual stresses at the start and the end of the path $\mathrm{AB}$ (horizontal line) were larger than those observed on the vertical path.

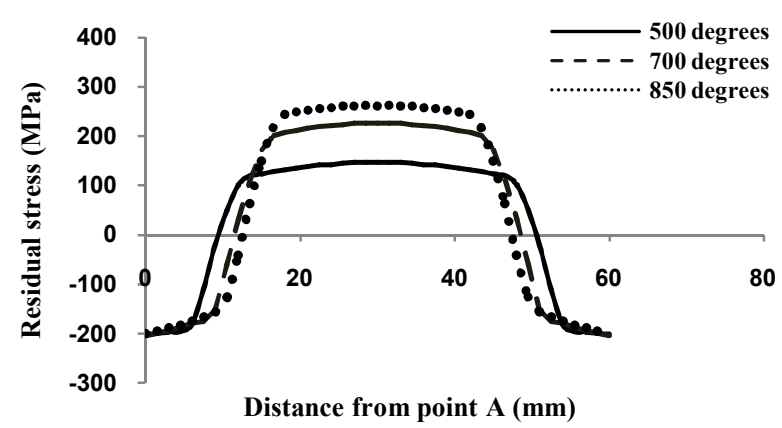

(a)

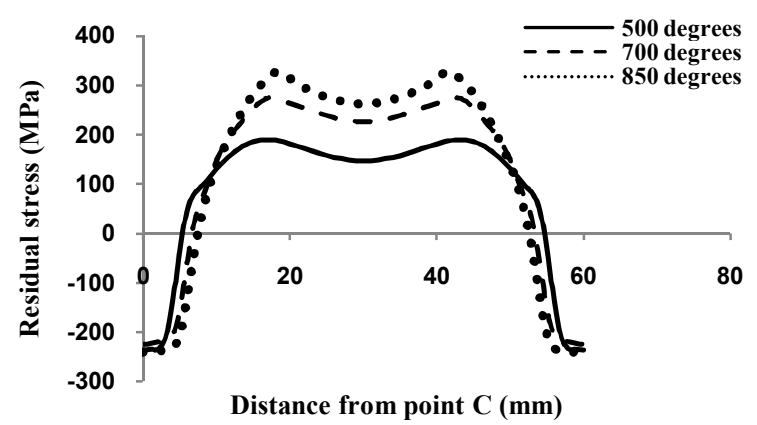

(b)

Figure 8. Residual stresses obtained from FE, (a) along centerline of cylinder (line $\mathrm{AB}$ ) in three samples and (b) along axis of cylinder (line $\mathrm{CD}$ ) in three samples 
TABLE 2. Mechanical and thermal properties of 316L

\begin{tabular}{|c|c|c|c|c|c|c|c|c|c|c|}
\hline \multirow[b]{2}{*}{ Properties } & \multicolumn{10}{|c|}{ Temperature $\left({ }^{\circ} \mathrm{C}\right)$} \\
\hline & 20 & 100 & 200 & 300 & 400 & 500 & 600 & 700 & 800 & 900 \\
\hline Specific heat $\left(\mathrm{J} / \mathrm{Kg}^{\circ} \mathrm{C}\right)$ & 492 & 502 & 514 & 526 & 538 & 550 & 562 & 575 & 587 & 599 \\
\hline Thermal conductivity $\left(\mathrm{W} / \mathrm{m}^{\circ} \mathrm{C}\right)$ & 14.12 & 15.26 & 16.69 & 18.11 & 19.54 & 20.96 & 22.38 & 23.81 & 25.23 & 26.66 \\
\hline Young's modulus (GPa) & 196 & 191 & 186 & 180 & 173 & 165 & 155 & 144 & 131 & 117 \\
\hline \multirow[t]{2}{*}{ Poisson's ratio } & 0.294 & 0.294 & 0.294 & 0.294 & 0.294 & 0.294 & 0.294 & 0.294 & 0.294 & 0.294 \\
\hline & \multicolumn{10}{|c|}{ Temperature $\left({ }^{\circ} \mathrm{C}\right)$} \\
\hline \multirow[t]{3}{*}{ Yield stress (MPa) } & 20 & \multicolumn{2}{|c|}{300} & 400 & \multicolumn{2}{|c|}{500} & 600 & \multicolumn{2}{|r|}{700} & 850 \\
\hline & 245.49 & \multicolumn{2}{|c|}{153.31} & 145.29 & \multicolumn{2}{|c|}{135.27} & 126.25 & \multicolumn{2}{|c|}{110.22} & 82 \\
\hline & \multicolumn{10}{|c|}{ Temperature $\left({ }^{\circ} \mathrm{C}\right)$} \\
\hline \multirow[t]{2}{*}{ Thermal expansivity $\left(1 /{ }^{\circ} \mathrm{C}\right)$} & $\mathbf{0}$ & & 30 & & 200 & & & 650 & & 800 \\
\hline & $1.2 \mathrm{e}^{-6}$ & & $\Delta \mathrm{e}^{-6}$ & & $1.25 \mathrm{e}^{-5}$ & 1.33 & & $1.47 \mathrm{e}^{-5}$ & & $1.5 \mathrm{e}^{-5}$ \\
\hline
\end{tabular}

3. 2. Simulation of Contour Method All stages of the contour method on a quenched cylinder were simulated. The model of the quenched cylinder was cut in half using the element removal technique. Width of the cutting was considered to be equal to $0.35 \mathrm{~mm}$ similar to the experimental parameter. The simulation was performed using elastic-plastic regim. To examine the effect of gradually cutting the specimen, removing of elements was carried out with three numbers of increments, one, twelve and sixty. Results of the contour method simulation are shown in Figures 9a to $9 \mathrm{c}$.

These residual stress distributions are along the horizontal path (line $\mathrm{AB}$ ). At the model with one increment, the cut was done simultaneously which was far from the reality and no effect of plasticity was observed. The more the number of increments the more visible was the effect of plasticity. As the cut proceeded through the stressed specimen it acted as a flaw or discontinuity which resulted in stress concentration and therefore plasticity. Figures $9 a, 9 b$ and $9 c$ show a growth in the effect of plasticity when the number of increments increased. This is more obvious when higher level of residual stresses in the sample quenched at $850^{\circ} \mathrm{C}$ was being measured (Figure $9 \mathrm{c}$ ).

It is valuable to notice that all residual stress distributions in Figure 9 were along line $\mathrm{AB}$ which was the cutting direction. Interestingly, this was not the case for the residual stress distributions along line $\mathrm{CD}$ which was the axis of the cylinder and normal to the cutting direction. The stresses along line $\mathrm{CD}$ are shown in Figures 10a to 10c. It is evident that the residual stress distribution along line $\mathrm{CD}$ preserved their symmetry unlike the distributions along line AB. This meant that the plasticity indicated to have more influence along the cutting direction than along the direction normal to it.

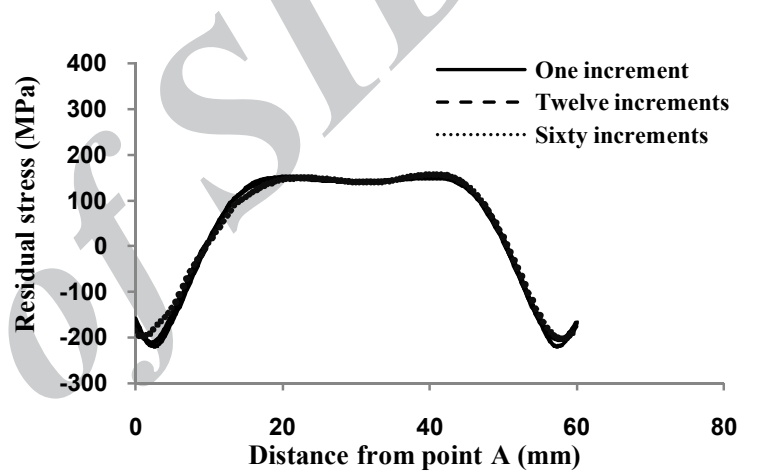

(a)

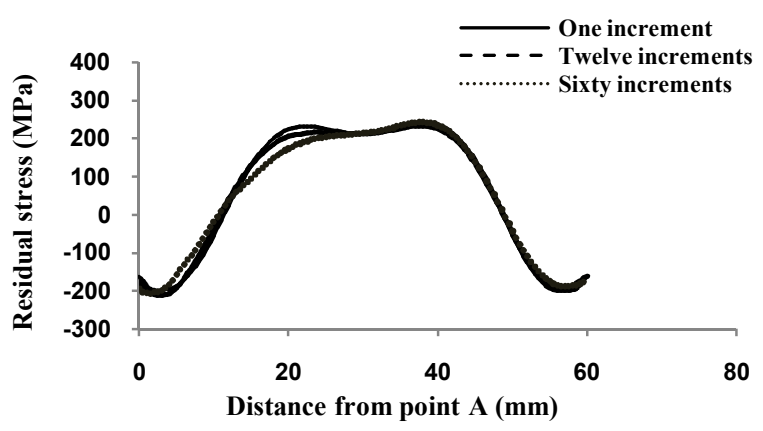

(b)

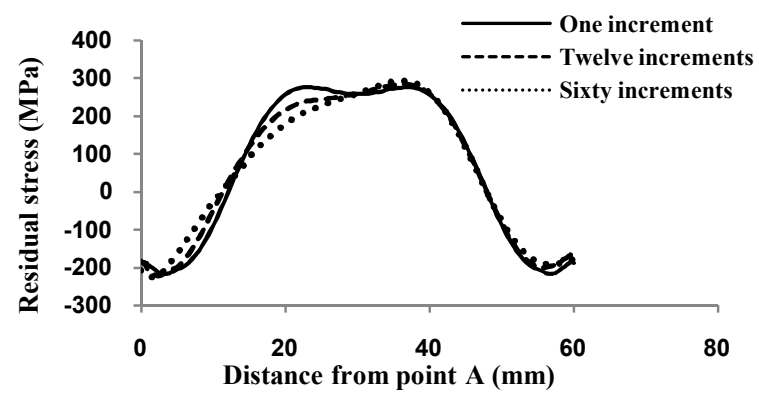

(c)

Figure 9. Obtained residual stresses by cutting in one, twelve and sixty increments along centerline of cylinder (line $\mathrm{AB}$ ) quenched at (a) $500^{\circ} \mathrm{C}$, (b) $700^{\circ} \mathrm{C}$ and (c) $850^{\circ} \mathrm{C}$ 


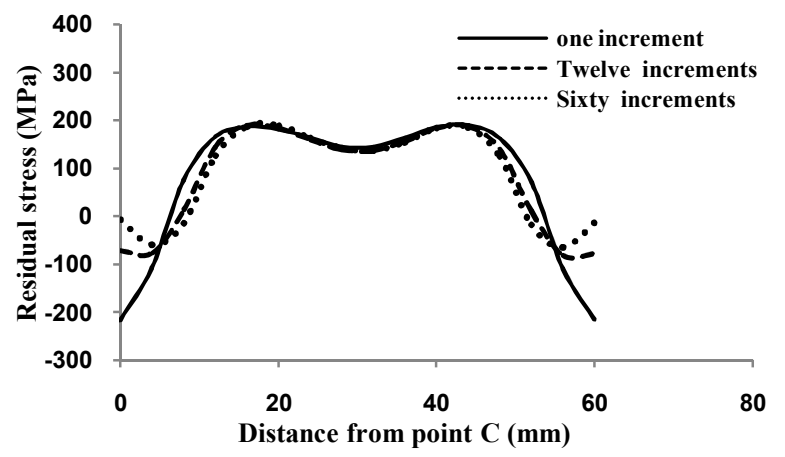

(a)

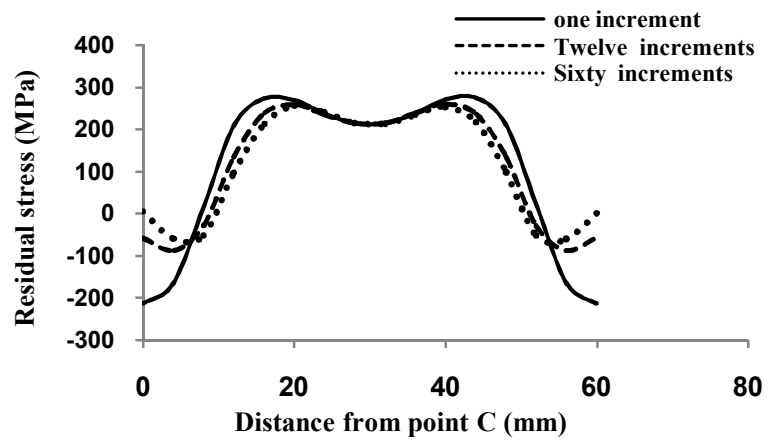

(b)

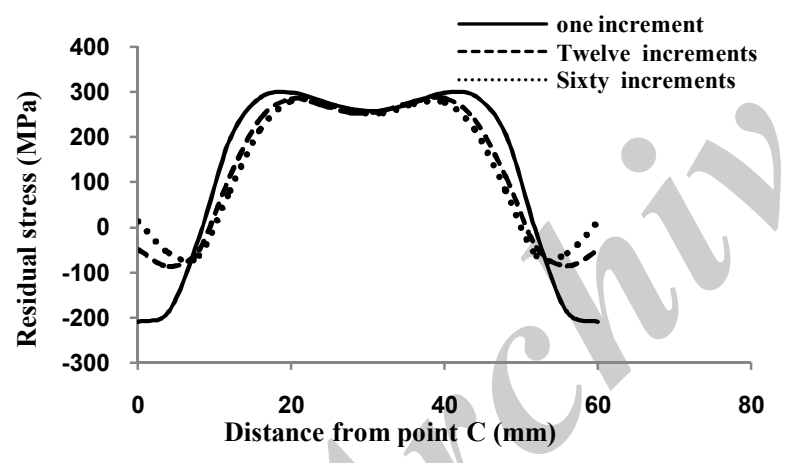

(c)

Figure 10. Obtained residual stresses by cutting in one, twelve and sixty increments along axis of cylinder (line CD) quenched at (a) $500^{\circ} \mathrm{C}$, (b) $700^{\circ} \mathrm{C}$ and (c) $850^{\circ} \mathrm{C}$

There was a possibility of an uncertainty due to the bulge error [24]. To eliminate the bulge error in the finite element simulation, the applied displacements as boundary conditions on end points of each cutting step must be improved. For this purpose, displacement of each one millimeter that obtained in final simulation must be subtracted from displacement of same point when the wire is over that point. For every three samples bulge error were excluded. The results are shown in Figure 11(a) along centerline of the cylinder (line $\mathrm{AB})$. For exclusion of the bulge error in the experimental data, an iterative finite element method was employed as detailed in [28]. This was performed using the ABAQUS user subroutines, DISP and SIGINI. The process was done for cylinder quenched at $850^{\circ} \mathrm{C}$. Figure 11(b) presents the stress distributions of $850^{\circ} \mathrm{C}$ sample for all three iterations along centerline of cylinder (line $\mathrm{AB}$ ). No significant influence was observed.

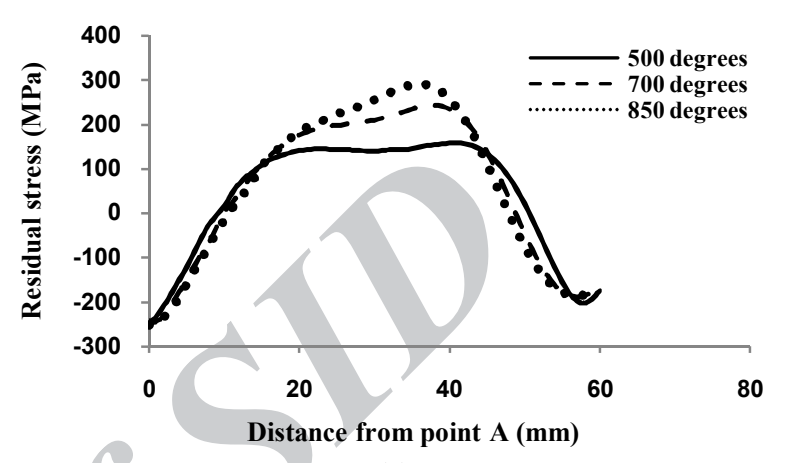

(a)

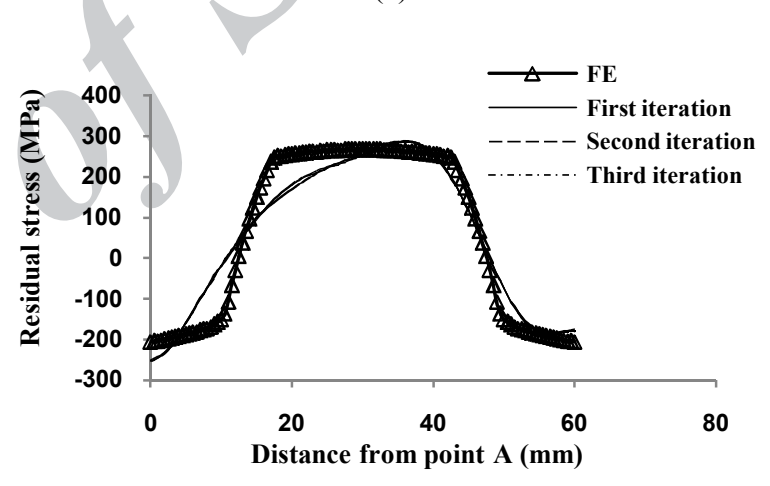

(b)

Figure 11. (a) Obtained residual stresses by simulation of cutting in 60 increments without bulge error along centerline of cylinder (line $\mathrm{AB}$ ) at $500^{\circ} \mathrm{C}, 700^{\circ} \mathrm{C}$ and $850^{\circ} \mathrm{C}$, (b) Residual stresses obtained by cutting simulation in first, second and third iterations of bulge errors excluding at $850^{\circ} \mathrm{C}$ along cylinder centerline (line $\mathrm{AB}$ ) compared with $\mathrm{FE}$ prediction.

\section{DISCUSSION}

Figures 12 and 13 compare the results of all different cases along centerline (line $\mathrm{AB}$ ) and axis of the cylinder (line $\mathrm{CD}$ ). The comparison between finite element simulations and the experimental results along line $\mathrm{AB}$ illustrates a very good match. It is evident that the effect of plasticity mentioned earlier along the cutting line was validated with the experimental findings. The experimentally measured residual stresses along the cutting direction confirmed the deviation of the residual stress distribution from those predicted by FE due to plasticity. This was the case for all three samples as 
shown in Figures 12a to 12b. Both experiment and finite element simulation indicated the non-symmetry distributions of residual stresses. Bulge error showed very small effects on the results apart from the near edges as can be seen.

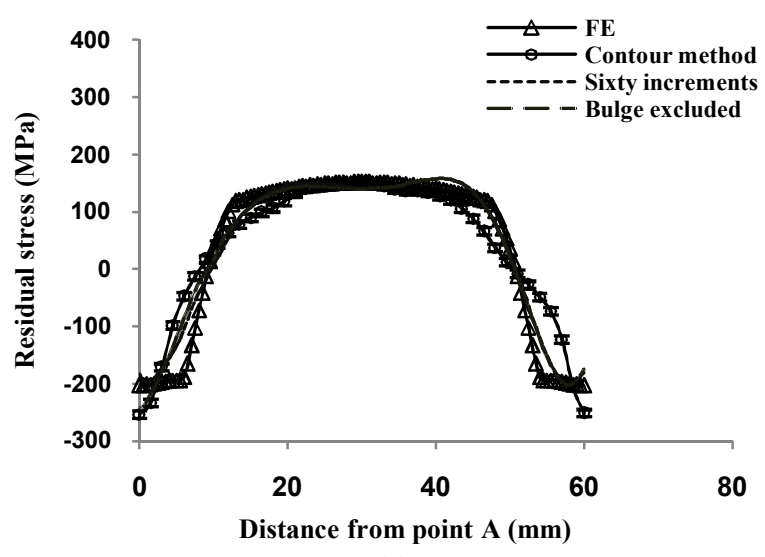

(a)

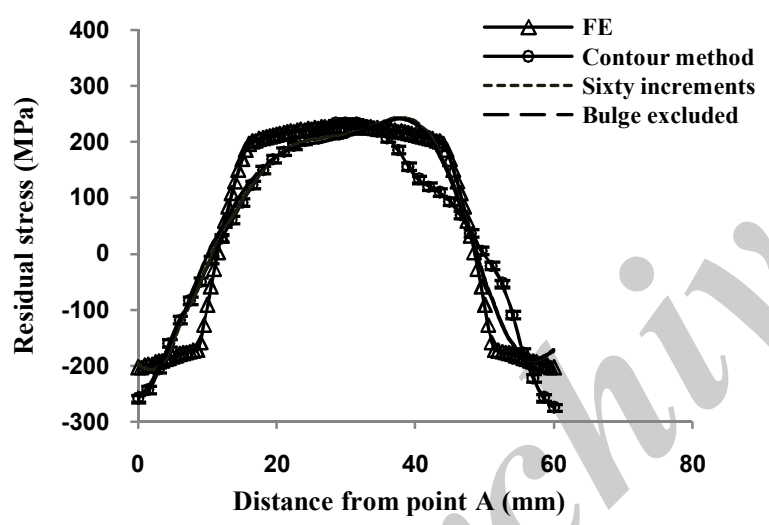

(b)

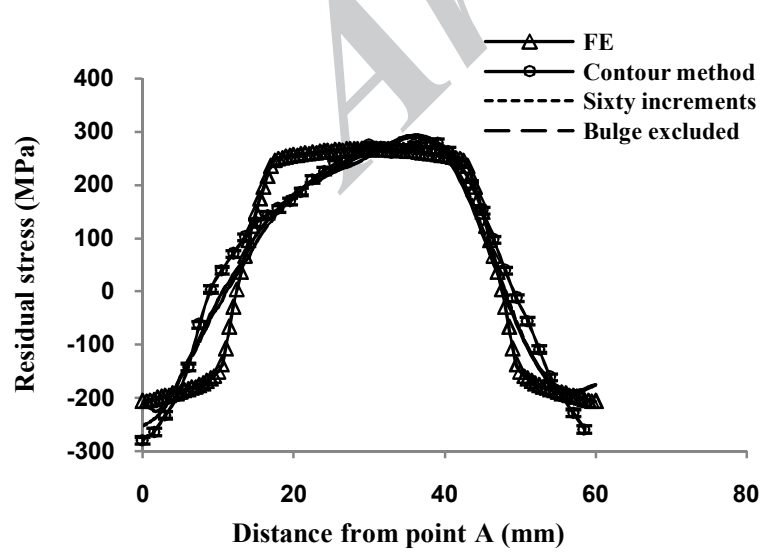

(c)

Figure 12. Comparing all residual stress distributions along centerline of the cylinder (line $\mathrm{AB}$ ) for the sample quenched at (a) $500^{\circ} \mathrm{C}$, (b) $700^{\circ} \mathrm{C}$ and (c) $850^{\circ} \mathrm{C}$

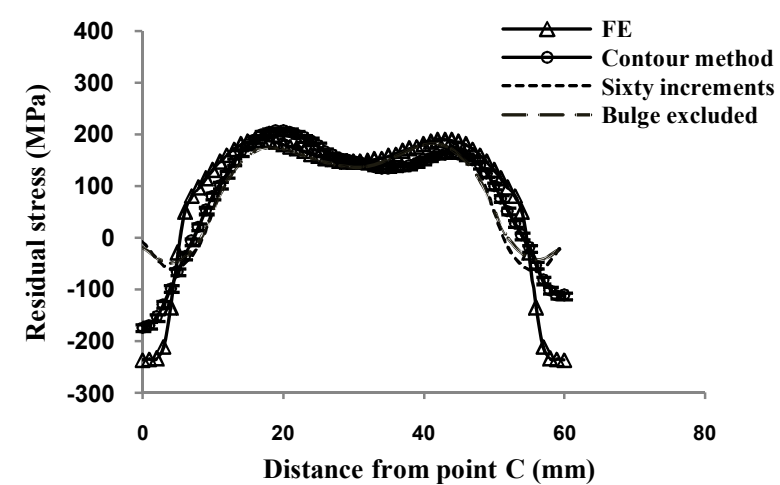

(a)

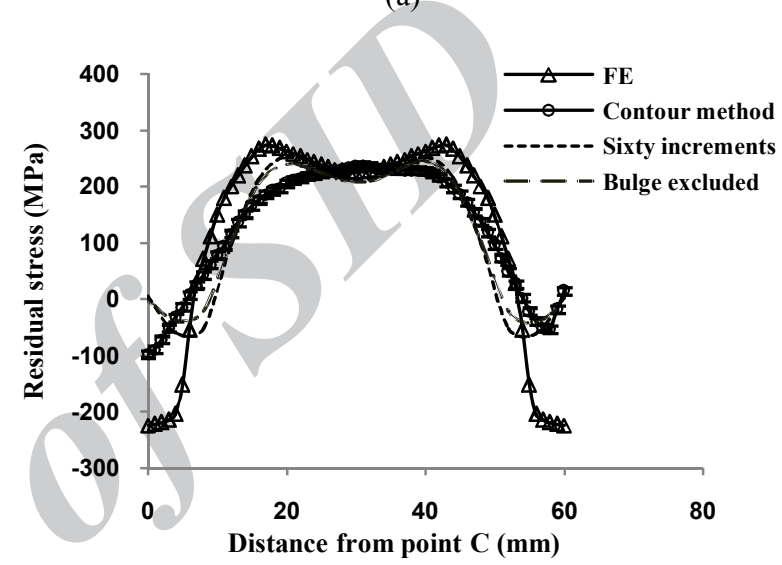

(b)

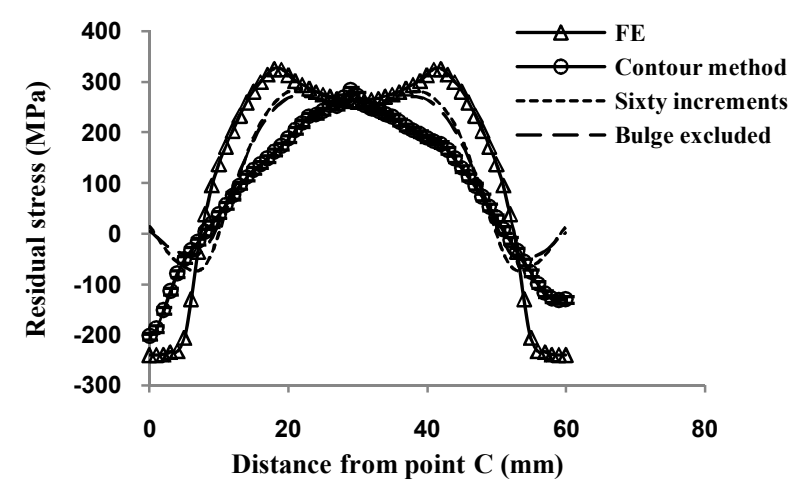

(c)

Figure 13. Residual stresses obtained by experimental approach, simulation of cutting in 60 increments and without bulge error in comparison with those predicted by finite element along axis of cylinder (line CD) at (a) $500^{\circ} \mathrm{C}$, (b) $700^{\circ} \mathrm{C}$ and (c) $850^{\circ} \mathrm{C}$

Figures $13 \mathrm{a}$ and $13 \mathrm{~b}$ show all residual stress distributions along the vertical line which is normal to the cutting direction. As predicted by finite element simulation of the contour method, the plasticity indicated smaller impact on the stress distributions. The experimental results also illustrated the same findings. 
Although, the difference between the experiments and finite element distributions were more noticeable along this path, both showed symmetrical distribution which was evidence of less influence of plasticity. As was expected, along line $\mathrm{CD}$, which is parallel to paths of probe motion, stresses that obtained near the edges showed a large difference with those predicted by finite element. This confirmed that CMM's results near the edges were not reliable. This effect can be reduced with a more accurate CMM device and a smaller probe.

\section{CONCLUDING REMARKS}

It can be concluded that:

1. The range of residual stresses in $850^{\circ} \mathrm{C}$ sample is more than other samples, as expected. And it is minimized for $500^{\circ} \mathrm{C}$ sample.

2. Experimental and numerical results have a good agreement for all three samples.

3. Increasing the steps of cutting in contour method simulation causes an increasing difference with finite element simulation. It happens because of more simulation of real condition in more cutting steps.

4. The steps of cutting in simulation of contour method indicated more effects on the accuracy of the results when the quenching temperature increased.

5. The plasticity effect increased with increase of the residual stresses, as expected. This occurred because of yielding a bigger region during the cutting process. Plasticity effect caused more difference between experimental and numerical results at $850^{\circ} \mathrm{C}$.

6. The plasticity effect appeared to be stronger along the cutting direction in comparison with the direction normal to it.

\section{REFERENCES}

1. Withers, P. and Webster, P., "Neutron and synchrotron x-ray strain scanning", Strain, Vol. 37, No. 1, (2001), 19-33.

2. Totten, G. E., "Handbook of residual stress and deformation of steel", ASM international, (2002).

3. Farrahi, G., Smith, D., Zhu, W. and McMahon, C., "Influence of residual stress on fatigue life of hot forged and shot blasted steel components", International Journal of EngineeringTransactions B: Applications, Vol. 15, No. 1, (2001), 79.

4. Mahmoudi, A., Truman, C. and Smith, D., "Using local out-ofplane compression (lopc) to study the effects of residual stress on apparent fracture toughness", Engineering Fracture Mechanics, Vol. 75, No. 6, (2008), 1516-1534.

5. Lu, J., "Handbook of measurement of residual stresses", Fairmont Press Lilburn, GA, (1996).

6. Cheng, W. and Finnie, I., "Examination of the computational model for the layer-removal method for residual-stress measurement", Experimental Mechanics, Vol. 26, No. 2, (1986), 150-153.

7. Rossini, N., Dassisti, M., Benyounis, K. and Olabi, A., "Methods of measuring residual stresses in components", Materials \& Design, Vol. 35, (2012), 572-588.

8. Moat, R., Pinkerton, A., Li, L., Withers, P. and Preuss, M., "Residual stresses in laser direct metal deposited waspaloy", Materials Science and Engineering: A, Vol. 528, No. 6, (2011), 2288-2298.

9. Prime, M. B., "Cross-sectional mapping of residual stresses by measuring the surface contour after a cut", TransactionsAmerican Society of Mechanical Engineers Journal of Engineering Materials and Technology, Vol. 123, No. 2, (2001), 162-168.

10. Prime, M. B., Hughes, D. J. and Webster, P. J., "Weld application of a new method for cross-sectional residual stress mapping", in SEM Annual conference on experimental and applied mechanics, Portland, Oregon, ASM. (2001), 608-611.

11. Prime, M. B., "The contour method: A new approach in experimental mechanics", in Proceedings of the SEM Annual Conference. Albuquerque, NM, USA. (2009).

12. Bueckner, H., "The propagation of cracks and the energy of elastic deformation", (1997).

13. Prime, M., Hill, M., DeWald, A., Sebring, R., Dave, V., and Cola, M., "Residual stress mapping in welds using the contour method", in International Conference, April. Vol. 15, (2002), 19.

14. Brown, D., Holden, T., Clausen, B., Prime, M., Sisneros, T., Swenson, H., and Vaja, J., "Critical comparison of two independent measurements of residual stress in an electron-beam welded uranium cylinder: Neutron diffraction and the contour method", Acta Materialia, Vol. 59, No. 3, (2011), 864-873.

15. Murugan, N. and Narayanan, R., "Finite element simulation of residual stresses and their measurement by contour method", Materials \& Design, Vol. 30, No. 6, (2009), 2067-2071.

16. Hacini, L., Van Lê, N. and Bocher, P., "Evaluation of residual stresses induced by robotized hammer peening by the contour method", Experimental Mechanics, Vol. 49, No. 6, (2009), 775-783.

17. Prime, M. B. and Martineau, R. L., "Mapping residual stresses after foreign object damage using the contour method", in Materials science forum, Trans Tech Publ. Vol. 404, (2002), 521-526.

18. Prime, M. B., Newborn, M. A. and Balog, J. A., "Quenching and cold-work residual stresses in aluminum hand forgings: Contour method measurement and fem prediction", in Materials science forum, Transtec Publications; Vol. 426, (2003), 435-440.

19. Turski, M. and Edwards, L., "Residual stress measurement of a 3161 stainless steel bead-on-plate specimen utilising the contour method", International Journal of Pressure Vessels and Piping, Vol. 86, No. 1, (2009), 126-131.

20. Frankel, P., Withers, P., Preuss, M., Wang, H.-T., Tong, J., and Rugg, D., "Residual stress fields after fod impact on flat and aerofoil-shaped leading edges", Mechanics of Materials, (2012).

21. Pagliaro, P., Prime, M. and Zuccarello, B., "Multiple stress components from multiple cuts for the contour method", in Proceedings of the XXXV AIAS Conference, September. (2006), 13-16.

22. Pagliaro, P., Prime, M. B., Swenson, H. and Zuccarello, B., "Measuring multiple residual-stress components using the contour method and multiple cuts", Experimental Mechanics, Vol. 50, No. 2, (2010), 187-194.

23. Dennis, R., Bray, D., Leggatt, N. and Turski, M., "Assessment of the influence of plasticity and constraint on measured residual stresses using the contour method", ASME. (2008). 
24. Prime, M. B. and Kastengren, A. L., The contour method cutting assumption: Error minimization and correction, in Experimental and applied mechanics, volume 6., Springer. (2011), 233-250.

25. Mahmoudi, A., Hossain, S., Truman, C., Smith, D. and Pavier, M., "A new procedure to measure near yield residual stresses using the deep hole drilling technique", Experimental Mechanics, Vol. 49, No. 4, (2009), 595-604.

26. Mahmoudi, A. H., Hosseinzadeh, A. R. and Jooya, M., Experimental calibration of the convection heat transfer coefficient in quenching process for a reliable prediction of residual stresses, in The International Conference on Experimental Solid Mechanics and Dynamics (X-Mech), Technology, U. o. S. a., Editor. 2012: Tehran, Iran.

27. Hibbitt, K., "Abaqus: User's manual: Version 6.1", Hibbitt, Karlsson \& Sorensen, Incorporated, (2000).

28. Prime, M. B. and Kastengren, A. L., The contour method cutting assumption, error minimization and correction", , in Proceeding of the SEM Annual Conference and Exposition on Experimental and Applied Mechanics, Indianapolis, I. U., Society for Experimental,, Editor. 2010: Mechanics.

\title{
Plasticity Effect on Residual Stresses Measurement using Contour Method
}

\author{
A .H. Mahmoudi, A. R. Hosseinzadeh, M. Jooya
}

Department of Mechanical Engineering, University of Bu-Ali Sina, Hamedan, Iran

Paper history:

Received 01 May 2013

Received in revised form 11 May 2013

Accepted 16 May 2013

\section{Keywords:}

Contour Method

Residual Stress

Plasticity

Finite Element

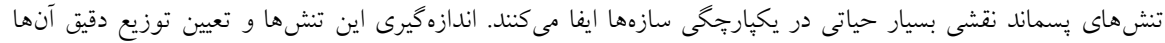

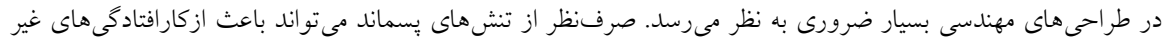

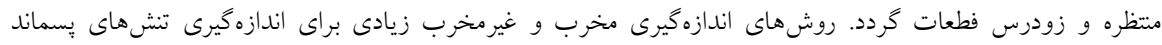

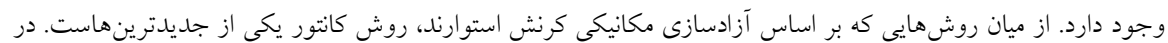

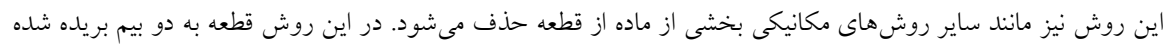

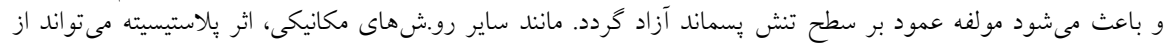

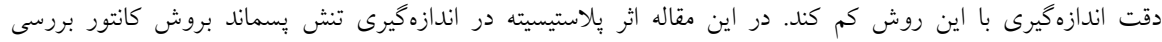

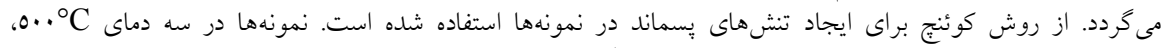

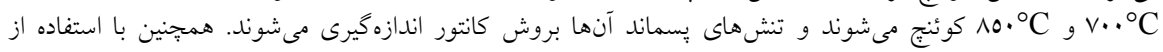

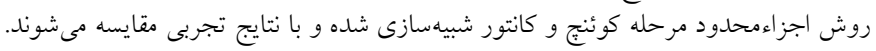

doi: 10.5829/idosi.ije.2013.26.10a.10 


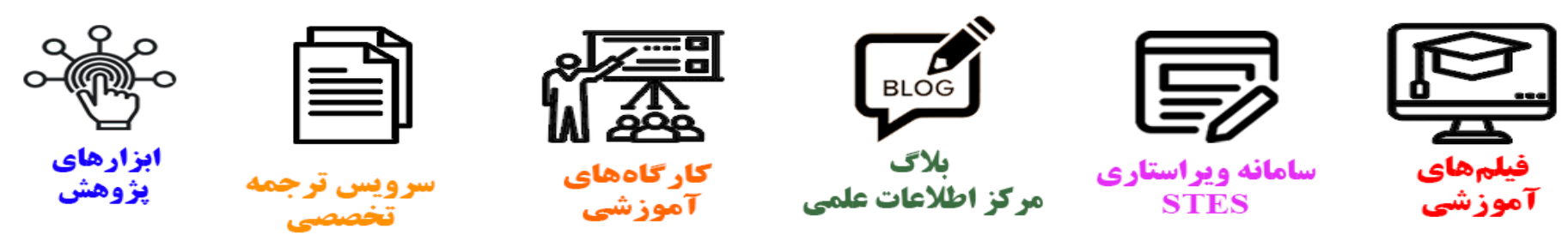

\section{(c)}

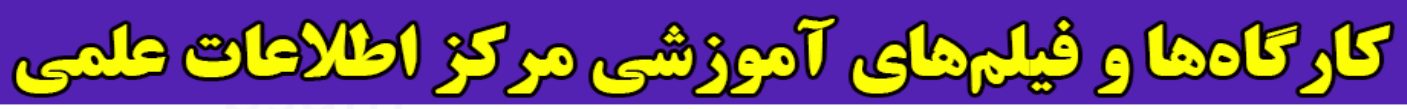
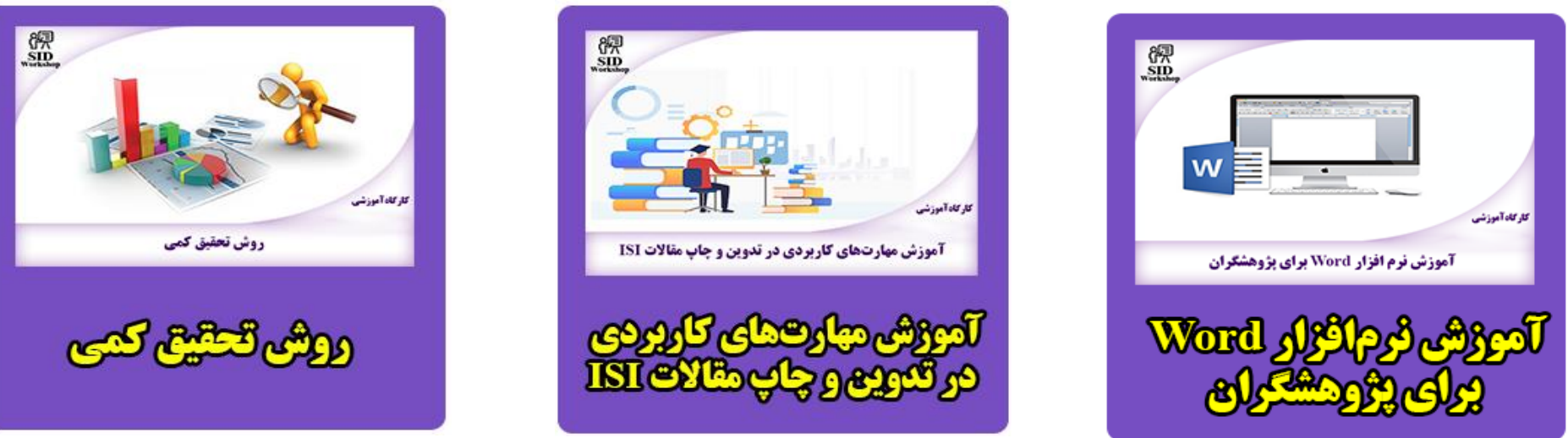